\title{
Mitigating barriers to addiction recovery in Aotearoa New Zealand: A lived experience perspective
}

Rachel Victoria Jowett, Michael Dale and Lareen Cooper, Massey University, Aotearoa New Zealand

\section{ABSTRACT}

INTRODUCTION: The New Zealand government's health surveys consistently identify that alcohol and other drug (AOD) addiction is an issue for New Zealanders. However, there is a lack of qualitative research on the lived experiences of health and social service professionals who have previous or current experience of AOD addiction in Aotearoa New Zealand.

METHODS: A constructivist approach was utilised, semi-structured interviews were conducted, and subsequent thematic analysis identified themes highlighting what contributed, and created barriers to, participants' successful AOD addiction recovery.

FINDINGS: Identification of nine themes illustrated that the barriers to AOD addiction recovery in Aotearoa New Zealand experienced by the research participants were systemic and preventable.

CONCLUSIONS: The recommendation of this research is that the lived experience of people who have experienced AOD addiction in Aotearoa New Zealand is better utilised in order to mitigate, and enhance, identified barriers, and contributors to, successful AOD addiction recovery.

KEYWORDS: Addiction; New Zealand; social work; lived experience; recovery
Existing Aotearoa New Zealand literature lacks qualitative research on alcohol and other drug (AOD) addiction by utilising the lived experience of people with AOD addictions. Participants in this research had all experienced AOD addiction and recovery, and then gone on to become qualified health and other social service professionals. The purpose of this research was to understand what contributes, and creates barriers to, successful AOD addiction recovery, subsequently addressing a gap in existing literature that identifies AOD addiction as a significant issue for New Zealanders and impacting negatively on holistic wellbeing for individuals, families and communities (Ministry of Health, 2015).
Available data on AOD use in Aotearoa New Zealand identifies AOD addiction as an issue, however it is inconsistent, lacks detail, and is dispersed across multiple domains of publicly accessible information. With some of the most current resources quoting data that are outdated, for example: the National Drug Policy 2015-2020 which cites data from 2007 (Ministry of Health, 2015).

The Annual Data Explorer publishes data gathered in the New Zealand Health Survey on an annual basis. An analysis of the data showed that recreational cannabis use had steadily increased over the past eight years, from $8 \%$ to $15 \%$. Alcohol was the most used substance with four out of five adults in
AOTEAROA NEW ZEALAND SOCIAL WORK 33(2), 45-55.

CORRESPONDENCE TO: Rachel Victoria Jowett rachel.jowett@hotmail.com 
Aotearoa New Zealand having used alcohol in the past year. Adults who had used alcohol problematically in the past year had decreased slightly from $26.2 \%$ in the 2015/ 16 survey but has remained relatively consistent since then; rates of problematic alcohol use in the past year were 24.9\% (as at the 2018/19 survey).

Methamphetamine use in Aotearoa New Zealand continues to rise albeit at comparatively much lower levels than alcohol and cannabis with $1 \%$ of adults having used methamphetamine in the past year. Of significance is the difference in prevalence rates for Māori as opposed to the rest of the population with problematic alcohol consumption in the past year being almost double the rates of the wider population; and methamphetamine use more than double that of the wider population. (Ministry of Health, 2019).

A second source of data was the National Wastewater Testing Programme, run by the New Zealand police from November 2018 to July 2019. Due to the brevity of this programme it is difficult to establish patterns of drug use in Aotearoa New Zealand from the data. For the duration of the programme, methamphetamine was the most used drug with approximately $15 \mathrm{~kg}$ of methamphetamine being consumed per week; MDMA was the second most common drug of use with a maximum of $7.9 \mathrm{~kg}$ being consumed each week (New Zealand Police, 2020).

Additionally, the New Zealand Drug Harm Index estimates that the total harm from drug use in Aotearoa New Zealand equates to $\$ 1.8$ billion (McFadden Consultancy, 2016). The National Drug Policy 2015-2020 also states that $12 \%$ of people who try substances will develop a substance use disorder (Inter-Agency Committee on Drugs, 2015); and that people using substances are more likely to have physical health issues such as Hepatitis C; have greater involvement with statutory agencies such as Oranga Tamariki; experience other social harms such as being involved in domestic violence incidents or engaging in behaviours such as drinking heavily whilst pregnant (Ministry of Health, 2015).

Existing data, albeit insufficient and inconsistent, do identify AOD addiction in Aotearoa New Zealand as a substantive, multi-faceted issue. AOD addiction is not, however, a new issue and additionally, is an issue that exists within a long history of moral and political narrative which has influenced if, and how, people experiencing AOD addiction access support. An understanding of the history of AOD issues in society provides a foundational understanding of the barriers to AOD addiction recovery already identified in the literature.

\section{Background and context}

Responses to AOD issues in society began with the moralisation of substance users, followed by criminalisation, and eventually leading to a medicalisation of substance use, which was posited as a brain disease and responded to by the medical sector. This finally culminated in a new age of AOD addiction epistemology that recognises the varied and complex factors that lead to the development and maintenance of a substance use disorder, requiring diverse holistic treatment responses tailored to each individual in order to meet their unique needs (Patil \& Giordano, 2010; Webster \& Bosmann-Wātene, 2003).

In Aotearoa New Zealand, addiction is largely still a pathologised phenomenon (Csiernik \& Rowe, 2003) and classified as a psychological disorder, using similar classification systems that define other mental health disorders (American Psychiatric Association, 2013; World Health Organisation, 2005). Critics of this perspective identify the weaknesses of reducing a complex phenomenon to a discrete set of symptoms with clear diagnosis, without adequate consideration of socio-cultural factors that an individual may 
be facing (Patil \& Giordano, 2010); especially that person's cultural worldview (Webster \& Bosmann-Wātene, 2003).

International research shows the impact that the current medical model has on the individual engaged in treatment; people being more likely to internalise stigma (Wiens \& Walker, 2015) in response to a treatment model that poses addiction as a symptom of internal dysfunction (Adams, 2016). This leads to outcomes such as exhibiting less agency over their alcohol use (Wiens \& Walker, 2015), highlighting the need to better align existing medical models with bio-psycho-social models. Further integrating sociologically based professions such as social work into the existing system would be an ideal option to achieve this change.

The social work perspective challenges views of addiction as solely an issue of internal dysfunction, instead recognising that a person is constantly engaged in transactional processes that take place between the person and the systems they interact with. The social work perspective would consider that it is these interactions that can become problematic and provide a basis for problematic biological, psychological or sociological functioning (Corcoran \& Walsh, 2010). This perspective best aligns with government guidelines on addressing AOD issues in New Zealand, with the National Drug Policy acknowledging the need for a holistic view of AOD addiction that not only responds to an individual but also their family, environment, community and employment (Ministry of Health, 2015).

\section{Literature review}

The literature review provided a better understanding of the existing literature on AOD addiction, both internationally and in New Zealand. Subsequently, no research was identified that answered the research question. However, the review identified the pervasive and systemic barriers to AOD addiction recovery helping to shape the interview questions designed to answer the research question: "What works in AOD addiction recovery?" The scope of the review included all research articles on AOD addiction between 2008 and 2018also included were any seminal texts on AOD addiction, even if they were published outside of the review timeframe.

International and Aotearoa New Zealand based research identifies stigma as a barrier to AOD addiction recovery and, of concern is that stigma is often perpetuated within support services (Brener et al., 2010; Butler \& Sheridan, 2010; Clarke et al., 2016; Csiernik \& Rowe, 2003; Deering et al., 2012; Gunn \& Canada, 2015; McCray et al., 2011; McKim, 2014; Roussy et al., 2015). For example, Aotearoa New Zealand research identified that stigma is perpetuated by staff attitudes in Opioid Treatment Services (Deering et al., 2012). Research investigating the attitudes of staff in primary health organisations also identified staff attitudes that perpetuated stigma. Research participants expressed beliefs that the drug misuse was the patients' "...own fault, that they are dirty people" (Butler \& Sheridan, 2010, p. 4).

Stigma was identified as a complex and pervasive barrier to AOD addiction recovery. Stigma was not only experienced when people were accessing health services but was also perpetuated in wider society, within peer groups, and was internalised by people experiencing AOD addiction. Stigma reduced the likelihood that people would seek help for an AOD addiction, and when they did seek help, they were less likely to engage successfully in AOD treatment.

Policy responses were also identified as a primary barrier to successful AOD addiction recovery; research both internationally and in Aotearoa New Zealand (Clear \& Schrantz, 2011; Drake et al., 2009; Miller \& Alexander, 2016; Pratt \& Clark, 2005) identified the ineffectiveness, and subsequent harm, of criminalising people experiencing AOD addictions. A recent Aotearoa New Zealand report stated that prisons have been shown 
to be a recruitment ground for further criminal and gang involvement often linked to the illicit drug trade; damage a person's employment, housing and familial prospects; and people in prison have high rates of undiagnosed and untreated mental health and addiction issues (Office of the Prime Minister's Chief Science Advisor, 2018).

Additionally, existing literature identified specific populations that face unique harms from AOD addictions which are inadequately addressed within existing systems. These populations were: Māori, youth, people with co-existing mental health issues, women, and families of those with $\mathrm{AOD}$ addiction issues.

In Aotearoa New Zealand, Māori are Tangata Whenua and have unique rights to tino rangatiratanga under the Treaty of Waitangi, a document that has been integrated as the foundation of multiple pieces of government legislation including the New Zealand Public Health and Disability Act (2000). Despite efforts to increase equity in social and health outcomes (Ministry of Health, 2008), Māori continue to experience higher rates of negative outcomes in regard to AOD addiction (Marie et al., 2008), including that Māori are more likely to be addicted to substances; and face greater harm from those addictions (Lyons \& Willott, 2008; Marie et al., 2008).

Aotearoa New Zealand research identified that multiple risk factors for youth in regard to substance misuse have increased in recent years with access to alcohol being easier after the "deregulation of the commercial environment, liberalisation of marketing controls, and the lowering of the age of legal purchase" (McCreanor et al., 2008, p. 939). These changes have coincided with a developing synthetic drug market which is pertinent to youth populations because most users of synthetic drugs are young adults aged between 12 and 24 years old (Davis \& Boddington, 2015). Despite youth being a targeted group for AOD support services, "young people seldom seek help for AOD problems and treatment services generally meet their needs poorly" (Christie et al., 2010, p. 406).

In Aotearoa New Zealand, approximately $12 \%$ of people will have an AOD addiction in their lifetime and $70 \%$ of these people will have co-existing mental health challenges (Ministry of Health, 2012). International research identified that, for people needing psychiatric medication, but still using illicit substances, the lack of consideration given to their complex contextual factors created an inadequate and at times dangerous pharmaco-centric response. Additionally, in the wider mental health sector, staff attitudes created barriers to service utilisation (Butler et al., 2011; Christie et al., 2010; Schlosser \& Hoffer, 2012; Staiger et al., 2011).

Women face disproportionate harm from substance misuse (Simpson \& McNulty, 2008) compounded by higher levels of stigma experienced by women, who are considered by wider society to have breached their traditional gender-defined roles by misusing substances (Lyons \& Willott, 2008; McCray et al., 2011; Reid et al., 2008; Sallmann, 2010). Women experiencing AOD addiction are more likely to have a drug using partner; are more likely to share injecting equipment; are at increased risk of HIV and Hepatitis C infection; are more likely to be involved in sex work; have higher vulnerability to psychiatric comorbidity including suicide attempts, eating disorders and post-traumatic stress disorder due to sexual and physical violence; and are more likely to have their children removed by child protection services (Simpson \& McNulty, 2008).

The role of families in AOD addiction and recovery emerged as a dominant theme. A subsequent review of the literature identified that children exposed to problematic drinking by parents have more behavioural and emotional issues, that there is a lack of family support services, and that families provide the highest levels of recovery capital—recovery capital being defined 
as emotional support, or support with practicalities such as housing and finances (Copello et al., 2010; Templeton et al., 2007; Tunnard, 2002).

The AOD sector was a key component of existing systems in which gaps were highlighted across the wider AOD workforce regarding existing workforce skills including an ability to be reflexive and responsive in their practice, and able to undertake holistic assessments that inform collaborative individualised treatment plans. Of interest, however, is that existing literature identified that the peer workforce was consistently named as an important contributor to successful AOD addiction recovery.

The literature identified that the defining of AOD addiction and subsequent treatment responses were primarily influenced by which profession was assessing and responding. This contested nature of the definition of AOD addiction, and subsequent treatment responses further perpetuated systemic inequities as, in Aotearoa New Zealand, the medical model of addiction is arguably still the dominant paradigm. Current literature, however, calls for a holistic approach to AOD addiction treatment, recognising the unique individual life experiences that lead to the development of an AOD addiction and requirement for an individually tailored, holistic treatment plan.

The literature review not only confirmed the validity of the research question but also assisted the formulation of an emergent hypothesis of what works in AOD addiction recovery. This hypothesis influenced the interview process by providing a foundational understanding of existing barriers to AOD addiction recovery, including: that stigma is pervasive and creates significant barriers to AOD addiction recovery; that existing policies compounded harm caused by AOD addiction; specific populations were not adequately supported; and finally, that the lack of staff training and skills in the AOD workforce created barriers to $\mathrm{AOD}$ addiction recovery.

\section{Ethical issues}

The ethical foundation was designed to ensure that the research was carried out in a way that was "respectful, humane, and honest" (Cohen \& Crabtree, 2008, p. 333), as well as being empathetic, collaborative and grounded in the notion of service (Cohen \& Crabtree, 2008) as, ultimately, social research faces the task of conducting research to create positive social change (Aotearoa New Zealand Association of Social Workers [ANZASW], 2007; Arksey \& Knight, 1999).

Small potential risks were identified including harm to participants when being asked to recount potentially traumatic experiences; harm to the researcher when receiving this information; and confidentiality of participants. The utilisation of existing external support systems was considered a possible solution for both participants and the researcher should any issues arise during the interviews. Confidentiality of participants was maximised by using locks on storage cabinets and password-protected devices, and pseudonyms. Cultural supervision was utilised to ensure that the interests of Māori were a key consideration throughout the research.

Informed consent was given by participants signing a consent form after reading the information sheet and having the opportunity to ask questions regarding the research. Participants were able to withdraw from the study at any point up until the research was published and had the opportunity to review and amend their interview transcripts. The researcher's name, qualification and job title were openly disclosed in the information sheet to mitigate any conflict of interest from the researcher knowing the participants in a professional or personal scope.

\section{Ethics approval}

A full ethics application was submitted to Massey University Human Ethics Committee 
(MUHEC), was considered by the Human Ethics Southern A Committee, and final confirmation of ethics approval was given on the 17th August 2017. The ethics application process was completed under the guidance of academic supervisors Michael Dale and Lareen Cooper. This research adhered to the Massey University Code of Ethical Conduct for research, teaching and evaluations involving human participants (Massey University, 2015).

\section{Methodology}

The ontological beginnings of this research were based in the "researchers' assumptions, existing knowledge, and reasons for engaging in research" (Starks \& BrownTrinidad, 2007, p. 1372). An exploration of these assumptions was necessary as the researcher believed that research is always a subjective process (Watson, 2005). These assumptions were twofold, firstly being based in the social work profession which respects the unique, rich and diverse life experiences of people (Nelson, 2012) and the systems they operate in (Engel \& Schutt, 2005, p. 11). With the goal of social work research being "not to come up with conclusions that people will like, to find answers that make our agencies look better or that suit our own personal preferences" (Engel \& Schutt, 2005, p. 18). Secondly, the researcher was a New Zealand/European woman who had personally experienced AOD addiction and recovery in Aotearoa New Zealand and gone on to be a qualified and registered social service professional. Ultimately, the primary purpose of this research was to value, respect and learn from people who were AOD professionals with lived experience of AOD addiction and recovery.

The epistemological foundation and corresponding research paradigm for this research project was constructivist, and the methods employed were qualitative. Constructivism being a process that posits the researcher as an observer in the world, transforming everyday practices into a series of representations, allowing for an analysis of these practices from a naturalistic approach and attempting to understand the meanings that people bring to them (Alvesson \& Skoldberg, 2009). The use of constructivism also filled a gap in local research highlighted in the literature review which showed a plethora of locally led positivist addiction research on AOD addiction; but limited qualitative research. Various researchers highlight the dominance of positivism in health-related research (Broom \& Willis, 2007; Cohen \& Crabtree, 2008), Prasad states that "this hijacking of routine problem solving by technical experts has some serious and undemocratic ramifications for society" (2005, p. 142), because only those with a certain level of knowledge are able to contribute to knowledge generation. Inadvertently, those who are marginalised in society, but who hold unique and valuable knowledge about social issues, will not have the ability to add their stories and experiences to academic literature (Prasad, 2005).

The method of purposive sampling was used to recruit participants (Broom \& Willis, 2007). Participants must have had lived experience of AOD addiction, treatment and recovery in Aotearoa New Zealand and been employed in the AOD sector in New Zealand within the last five years. Specific demographic data regarding ethnicity were not collected - this is recognised as a potential limitation of this research because consideration of the influence of culture on AOD addiction recovery was not specifically considered in the interview schedule. An advertisement was placed in the Matua Raki addiction sector bulletin, potential participants were able to email the researcher directly and were sent the information sheet via email. Subsequently, an unintentional snowballing effect took place whereby interested participants notified other potential participants about the research. The outcome of participant recruitment was that eight research participants were recruited. One-on-one, hour-long, semi-structured 
interviews were conducted face to face, via Skype, or phone.

Semi-structured interviewing was chosen as the primary data collection method because it provided "a means for exploring the points of view of ... research subjects, while granting these points of view the culturally honoured status of reality" (Shaw \& Gould, 2001, p. 143). It allowed the researcher to observe patterns across the group's behaviour (Broom \& Willis, 2007); created a naturalistic conversational setting and one whereby only minimal steerage during the interview was required; this allowed the participants to discuss the aspects of the broader topic that were important to them (Arksey \& Knight, 1999). The interview schedule was flexible so that questions could be added or subtracted according to each successive interview outcome (Rubin \& Babbie, 2013).

Interviews were recorded using an audio recording device and transcribed verbatim, notes were written as soon as possible after the interview ended-this was done to capture extra details from the interview such as mood and body language that the audio recording was not able to capture (Arksey \& Knight, 1999); data were then analysed using inductive thematic analysis. At all stages of the thematic analysis, a research journal was utilised as this provided a reflective space where personal assumptions about emergent themes could be unpacked and the patterns and broader thematic story in the data could be considered. A thematic map emerged during the data analysis which consisted of barriers to AOD addiction recovery, and contributors to AOD addiction recovery.

\section{Findings}

The findings are presented in this article under two subheadings: Barriers to recovery, and Contributors to recovery. Participants had a range of personal and professional experiences with ages ranging from 22 to 50 years old and having been in AOD addiction recovery from 5 to 40 years. Participants had experienced AOD addiction, treatment and recovery in Aotearoa New Zealand and other countries. Participants had experienced addiction to a range of drugs including, alcohol; amphetamines; opioids; cannabis; ecstasy; LSD; and pharmaceutical drugs such as Temazepam ${ }^{\circledR}$. Participants held qualifications such as: Bachelor's degrees; Postgraduate diplomas; Master's degrees; and PhDs. Participants had been employed in non-government organisations (NGOs); the Corrections System; AOD inpatient rehabilitation services; hospital and acute care settings; national leadership positions; in self-employed counselling roles; and as lecturers in Aotearoa New Zealand universities and polytechnics.

\section{Barriers to recovery}

The results in this research identified barriers to AOD addiction recovery. With a primary barrier being participants' experiences of stigma in their communities, in the workplace and within peer recovery groups. Participant three expressed disbelief at how pervasive stigma still is, "there is a real lack of understanding, lack of compassion for people with addiction issues."

Participants also found that stigma prevented them from being able to define their own recoveries and lives. Some participants led fragmented, dual lives to avoid stigma. This added stress into their personal and professional lives. Participant six hinted at the repercussions she would face if she were to disclose her lived experience in the workplace:

I am still most comfortable when I am in an NA meeting or with sex workers because it is still my stronger identity so there is always this work that I do about managing my identity. Because I never reveal in these settings my true identity because they are not forgiving.

Participants also found that working in peer roles created barriers to wellbeing in AOD addiction recovery, being stigmatised 
by colleagues caused participants to lose passion for their roles. As described by participant four, "it has taken its toll there have been times that I have thought, I cannot do this."

Participants also discussed their perceptions of systemic barriers in New Zealand, starting with the lack of AOD education in secondary schools. Participant two described the lengths she went to to source her own information on AODs as she was dissatisfied with the abstinence-based education taught at her college - a process that unintentionally led (by searching for information online) to her finding out how to combine various drugs to maximise their effects.

The failures of welfare support systems were also discussed, participants considered Work and Income case managers and child protection social workers to be ineffective when working with people experiencing AOD addictions. In addition, current welfare and housing systems were considered complex to navigate, with people not being able to access support to meet their basic essential needs (income and housing)_both being considered as vital in creating a successful foundation in AOD addiction recovery. Barriers to AOD addiction recovery had also been caused by the AOD sector itself through a lack of diversity in AOD interventions; an overfunding of costeffective methods such as brief interventions; the complex structure of the AOD sector and subsequent difficulties navigating the sector.

The criminal justice system was also identified as a barrier to AOD addiction recovery in Aotearoa New Zealand. Participants recounted instances of being intentionally targeted by NZ Police for menial infringements due to being known substance users. Participants advised that the Corrections system failed to provide holistic ongoing support for people with AOD addictions, often sending people back to unchanged, unhealthy environments. Participants expressed concern that people were being locked into cycles of crime, violence and AOD addiction due to a lack of systemic change in Aotearoa New Zealand. An issue further perpetuated by the criminalisation of people using substances.

Current funding models in Aotearoa New Zealand were considered a barrier due to their focus on cost-management, and subsequent inadequate funding increases comparative to increasing demand for services leading to increased waiting lists, limited staff capacity to provide care, and limited resources. Service collaboration and holistic care were not considered to be supported by existing funding models. Participant four described the impact that the Request for Proposals (RFP) process had on her service:

The silo thinking, the people not talking to people, so one of the things I have watched our service do really well is build relationships with other organisations who see youth as well. There were some issues to resolve initially because I think people thought we were taking money out of the sector.

Furthermore, participants also identified barriers to AOD addiction recovery created by OST services; OST was viewed as punitive, which left participants too scared to be honest about their substance use. Participants also expressed that the overmedicalisation of OST services had taken away holistic recovery support options, stating that OST services now play an active role in encouraging people to stay on OST medication, even if a person decides that is no longer their recovery goal. Participant five recalled his historic personal experiences, as well as a friends' current experience:

... he is coming off methadone, the clinic just tried every technique and manipulation I would say by the psychiatrist with the help of the socalled counsellors, they are not really counsellors they are just case managers, to keep him on the dose that he is on. Like they do not like people coming off and they say "oh it does not really 
work and you should just stay on it a bit longer," which is the opposite of "well done that is really amazing how can we support you to come off?"

Participants recalled that the fracturing of the AOD sector that occurred between professionals who held opposing ideologies (harm reduction vs. abstinence), created conflict within the sector, this conflict created barriers for people trying to access the type of AOD addiction support that was right for them. Participant seven recalled the impact of conflict within the AOD sector:

When harm reduction came in there was a polarisation in the sector it was either harm reduction or abstinence, and there was no matching of the person in front of you to the right way. What happened was that a lot of people went underground.

The women who participated in this research had unique experiences of trauma in AOD addiction, relationships and motherhood that made it more difficult for them to access and remain in AOD addiction treatment and recovery. Participant four described her traumatic experience with childbirth and being locked in seclusion almost immediately after giving birth:

For the first four days of my daughter's life I did not get to see her, they would not let me, they tranquillised me they stuck me in seclusion, I just remember screaming for days, probably about 48 hours, please let me see my daughter.

Interestingly, participant experiences, both personal and professional, identified barriers that were wholly systemic. These included the pervasive nature of stigma, which was perpetuated by wider society, by support services, by peers, by colleagues (even once participants had entered recovery), and interestingly, as internalised stigma which prevented participants from contributing valuable knowledge. Organisational barriers were perpetuated by welfare services, child protection services, the AOD sector, the criminal justice system, existing funding models and underfunding of the AOD sector, OST services, the conflicting paradigms within the AOD sector, and within service responses to women experiencing AOD addiction.

\section{Contributors to successful recovery}

What was also identified in the results of this study were the factors that contributed to successful AOD addiction recovery. Participants stated that it was the ability to define their own recovery that contributed to their success and this subsequently led to the development of a redemptive self. Enabling them to gain employment that was meaningful to them by giving back to people who needed support, in turn reinforcing their personal recovery.

Participants highlighted the components of the AOD workforce that contributed to AOD addiction recovery. One component was an AOD professional who could build an effective therapeutic relationship with participants. For some participants this was an AOD professional with lived experience of AOD addiction, adding a dimension of trust and rapport that could not be emulated by AOD professionals who did not have lived experience.

Career progression also contributed to AOD addiction recovery, often beginning with entry into tertiary study and continuing once employed in their chosen profession. Participants recalled being supported and respected by colleagues and managers, which further contributed to their successes. Participants also accredited their own internal processes and external supports such as good boundaries, ethics and supportive friends and families, as a key aspect of their continued success in AOD addiction recovery, especially when working in professional roles became challenging.

Other supports that contributed to successful AOD addiction recoveries included: support provided by community based social services; access to income and housing; 
having family and friends that supported them in their AOD addiction and recovery, even though these support people did not always understand their AOD addiction or how best to support them; support groups run within AOD support services; twelvestep groups; residential treatment; and gender-specific support services.

\section{Discussion}

The most recent workforce development plan for the AOD sector states that healthcare must be led by the people accessing services (Ministry of Health, 2018). However, research in Aotearoa New Zealand (Deering et al., 2011; Deering et al., 2012) and internationally (Bassuk et al., 2016; Boisvert et al., 2008; Brener et al., 2010) supports participants' experiences whereby they were not always empowered to lead their treatment and recovery process. Each participant was able to recall times when they had not been at the centre of care planning and times when they had been. It was the times when they had led their AOD addiction recovery that led to successes.

The barriers to AOD addiction recovery identified in this research are systemic and preventable. There is arguably a greater role for social work in the AOD sector in order to mitigate these barriers and enhance the contributors to successful AOD addiction recovery. Navigating the AOD sector is a confusing process, fraught with stigmatising experiences, and people with AOD addictions would benefit from having social work support to walk alongside them, providing advocacy support when needed, to ensure that the person is able to access holistic assessment and individualised treatment options. Additionally, the role of the lived experience practitioner cannot be overlooked here. While participants in this study valued the support of professionals with lived experience of AOD addiction, existing systems do not support professionals to safely disclose their lived experience and integrate this into their practice.

\section{Conclusion}

This research highlighted that people with AOD addictions are the experts in their own lives. These people are extraordinarily resilient and resourceful and, if given the right support, can harness these strengths and engage in recovery and life, in a meaningful and purposeful way. People who have been the most excluded go on to challenge, resist and change Aotearoa New Zealand society and systems in order to ensure those coming behind them face fewer barriers to AOD addiction recovery than they did.

\section{Limitations}

The limitations relate to the small sample size and subjective nature of the research results. Additionally, seven out of eight participants had been in AOD addiction recovery for more than 15 years, meaning that current issues with AOD addiction in Aotearoa New Zealand were not necessarily captured. Inherent ethnocentrism due to the researcher's $\mathrm{NZ}$ / European ethnicity is also recognised as a limitation. Further research into the lived experience of Māori professionals who are in AOD addiction recovery would be useful, given the current context of AOD addiction disproportionately harming Māori communities and ongoing inequities related to colonisation and subsequent removal of tino rangatiratanga from tangata whenua in Aotearoa New Zealand.

Accepted 16 September 2021

Published 1 September 2021

\section{References}

Adams, P. J. (2016). Switching to a social approach to addiction: Implications for theory and practice. International Journal of Mental Health and Addiction, 14(1), 86-94. https://doi.org/10.1007/s11469-015-9588-4

Alvesson, M., \& Skoldberg, K. (2009). Reflexive methodology: New vistas for qualitative research. SAGE.

American Psychiatric Association. (2013). Diagnostic and statistical manual of mental disorders (5th ed.). American Psychiatric Publishing.

Aotearoa New Zealand Association of Social Workers. (2007). Code of ethics. https://anzasw.nz/wp-content/ uploads/Code-of-Ethics.pdf 
Arksey, H., \& Knight, P. (1999). Interviewing for social scientists: An introductory resource with examples. Sage Publications.

Bassuk, E. L., Hanson, J., Greene, R. N., Richard, M., \& Laudet, A. (2016). Peer-delivered recovery support services for addictions in the United States: A systematic review. Journal of Substance Abuse Treatment, 63, 1-9. http://doi.org/10.1016/j.jsat.2016.01.003

Boisvert, R. A., Martin, L. M., Grosek, M., \& Clarie, A. J. (2008). Effectiveness of a peer-support community in addiction recovery: Participation as intervention. Occupational Therapy International, 15(4), 205-220.

Brener, L., Von Hippel, W., Von Hippel, C., Resnick, I., \& Treloar, C. (2010). Perceptions of discriminatory treatment by staff as predictors of drug treatment completion: Utility of a mixed methods approach. Drug \& Alcohol Review, 29(5), 491-497.

Broom, A., \& Willis, E. (2007). Competing paradigms and health research. In M. Saks \& J. Allsop (Eds.), Researching health: Qualitative, quantitative and mixed methods. (pp. 16-31). Sage Publications.

Butler, R., \& Sheridan, J. (2010). Innocent parties or devious drug users: The views of primary healthcare practitioners with respect to those who misuse prescription drugs. Harm Reduction Journal, 7(21). https://doi. org10.1186/1477-7517-7-21

Butler, T., Indig, D., Allnutt, S., \& Mamoon, H. (2011). Cooccurring mental illness and substance use disorder among Australian prisoners. Drug \& Alcohol Review, 30(2), 188-194.

Christie, G., Merry, S., \& Robinson, E. (2010). Do young people attending addiction services differ from those attending youth mental health services?. Drug \& Alcohol Review, 29(4), 406-412.

Clarke, K., Harris, D., Zweifler, J. A., Lasher, M., Mortimer, R. B., \& Hughes, S. (2016). The significance of harm reduction as a social and health care intervention for injecting drug users: An exploratory study of a needle exchange program in Fresno California. Social Work in Public Health, 31(5), 398-407. https://doi.org/10.1080/19371918.2015.1137522

Clear, T. R., \& Schrantz, D. (2011). Strategies for reducing prison populations. The Prison Journal, 91(3), 138-159.

Cohen, D. J., \& Crabtree, B. F. (2008). Evaluative criteria for qualitative research in health care: Controversies and recommendations. Annals of Family Medicine, 6(4), 331-339. https://doi.org/10.1370/afm.818

Copello, A., Templeton, L., \& Powell, J. (2010). The impact of addiction on the family: Estimates of prevalence and costs. Drugs: Education, Prevention and Policy, 17(1), 63-71.

Corcoran, J., \& Walsh, J. (Eds.). (2010). Clinical assessment and diagnosis in social work practice (2nd ed.). Oxford University Press.

Csiernik, R., \& Rowe, W. S. (Eds.). (2003). Responding to the oppression of addiction: Canadian social work perspectives. Canadian Scholars' Press.

Davis, C., \& Boddington, D. (2015). Teenage cardiac arrest following abuse of synthetic cannabis. Heart, Lung and Circulation, 24(10), 162-163. http://doi.org/10.1016/j. hlc.2015.04.176

Deering, D., Horn, J., \& Frampton, C. M. A. (2012). Clients perceptions of opioid substitution treatment: An input to improving the quality of treatment. International Journal of Mental Health Nursing, 21(4), 330-339. https://doi. org/10.1111/j.1447-0349.2011.00795.x

Deering, D. E. A., Sheridan, J., Sellman, J. D., Adamson, S. J., Pooley, S., Robertson, R., \& Henderson, C. (2011). Consumer and treatment provider perspectives on reducing barriers to opioid substitution treatment and improving treatment attractiveness. Addictive Behaviors, 36(6), 636-642. https://doi.org/10.1016/j. addbeh.2011.01.004

Drake, E. K., Aos, S., \& Miller, M. G. (2009). Evidence-based public policy options to reduce crime and criminal justice costs: Implications in Washington State. Victims and Offenders, 4(2), 170-196.

Engel, R., \& Schutt, R. (2005). The practice of research in social work. Sage Publishing.

Ministry of Health. (2018). Mental Health and Addiction Workforce Action Plan 2017-2021 (2nd ed.). Author.

Watson, C. (2005, May). Living the life of the social inquirer: Beginning educational research. [Paper presentation] Forum Qualitative Sozialforschung/Forum: Qualitative Social Research.

Webster, J., \& Bosmann-Wātene, G. (2003). Walking in two worlds: A critique of the diagnostic and statistical manual of mental disorders from a perspective of Te Ao Māori. Social Work Review, 15(3), 8-11.

Wiens, T. K., \& Walker, L. J. (2015). The chronic disease concept of addiction: Helpful or harmful? Addiction Research \& Theory, 23(4), 309-321. https://doi.org/10.3 109/16066359.2014.987760

World Health Organisation. (2005). International statistical classification of diseases and related health problems (10th ed.). http://apps.who.int/classifications/icd10/ browse/2016/en 